\title{
Drastic Effects of Asian Financial Crisis on Macroeconomic Structural Changes in Lao PDR
}

\author{
Sorphasith XAISONGKHAM* Liuxia Kheuakham Bounvilay Phetphongphanh Savangchakavane \\ School of Business, Zhengzhou University, 100 Science Avenue, Zhengzhou, Henan, 450001, China
}

\begin{abstract}
More than a decade that the world economy has suffered with the destructive incidents from Asian Financial Crisis (AFC) occurred in 1997 and global financial crisis in 2008. Therein, the inception of AFC was derived from Thailand, and Lao PDR also treated as one of the most affected countries from AFC. This article attempts to discover innovative empirical evidence by identifying the drastic effects of AFC on macroeconomic structural changes in Lao PDR. By utilizing a special technique and superior method. Say, Zivot \& Andrews structural break unit root testing developed by (Zivot \& Andrews, 1992) to endogenously determine a one-time structural break, and the quarterly time series data also adopted in the period of 1990Q1-2006Q4. The empirical evidence substantiated the disastrous incident of AFC had initially affected on exchange rate (1997Q2), followed by consumer price index (1997Q2) and broad money (1997Q2) in the second quarter respectively, whilst total reserves was affected by AFC at the beginning of 1998 (1998Q1) and transmitted its shock to other macroeconomic variables in long run. Similarly, the outcomes strongly averred that AFC has engendered to drastic effects on macroeconomic structural changes in Lao PDR specifically the domestic currency has intensely depreciated (US/KIP) in the history of Lao PDR up to the present. Moreover, policy recommendations were proposed in this paper.
\end{abstract}

Keywords: Zivot \& Andrews Structural Break, Asian Financial Crisis, Macroeconomics Variables, Lao PDR.

DOI: $10.7176 /$ RJFA/11-22-05

Publication date: November $30^{\text {th }} 2020$

\section{Introduction}

Nowadays, global economy is rapidly growing after suffering and recovering from devastating crisis namely Asian financial crisis (Henceforth called AFC), which was taken place in 1997 and followed by global financial crisis in 2008. In the main, the disastrous circumstances of AFC had conducted to the new adjustments of economic structure changes in numerous countries. Simultaneously, monetary and fiscal policymakers as well as central bank were facing with the incredible nightmare because the AFC crisis had transmitted to the serious failures of efficient and effective management system for economic mechanisms. Likewise, the financial crisis had also led to negative impact on various economic structures namely capital formation, foreign trade, foreign direct investment, export, import, public dept, stock price, capital inflow and outflow, volatility of exchange rate and other macroeconomics variables.

On balance, the AFC commenced in July 1997 and the seed of AFC occurred from Thailand due to a financial debacle for Thai currency (Bath) and it took place after the government of Thailand had announced to float domestic currency. At the same time, Thailand was lacked of foreign currency to uphold its currency as well as retaining liquidity status compared to US dollars in economic system. Therein, one of the most affected countries from AFC consisted of Thailand, Indonesia and South Korea and followed by Hong Kong, Lao PDR, Malaysia and Philippine respectively, which most of Southeast Asia nations and japan had slumped their currency (Yamazawa, 1998). Meanwhile, the nominal gross domestic product of ASEAN countries dropped by $\$ 9.2$ billion and $\$ 218.2$ billion in 1997 and 1998 respectively. It also fell by $\$ 170$ billion in 1998 and covered around 33.1\% of nominal GDP in 1997 for South Korea. In addition, it can be explicitly seen that numerous nations were prodigiously hurting from AFC, enormous businesses were also collapsed. As a drastic consequence, there were millions of people fell below the property line during 1997-1998.

Lao PDR is one of the ASEAN countries burdened prodigious issues apart from three most affected countries (Thailand, Indonesia and South Korea) namely the economic growth in Lao PDR declined little from $6.92 \%$ in 1996 to $6.87 \%$ in 1997 and drastically continued to drop down $3.96 \%$ in 1998 whilst the real interest rate was drastically from $11.67 \%$ in 1996 to $-29.93 \%$ and $-42.09 \%$ of 1998 and 1999 respectively. The level of inflation rate highly rose in the spanning of $1997-1999$ and increased by $13.02 \%$ in 1996 to $19.35 \%, 84.50 \%$ and $127.97 \%$ in the next three years (1997, 1998 and 1999) and consumer price index was doubled increase from 8.94 in 1997, changed over 17.08 and 38.48 during 1998 and 1999 in succession. Meanwhile, the proportion of total reserve to total external debt dropped down by $7.78 \%$ in 1996, continually declined to be $5.03 \%$ and $4.76 \%$ in 1997 and 1998 respectively. Therefore, this paper aims to disentangle and uncover the long skeptical and debatable questions namely how the AFC influences on macroeconomic structural changes in Lao PDR, what are the most affected macroeconomics variables under the drastic effects of AFC. Similarly, this article will be applied a newly special technique as well as advanced econometric approach developed by (Zivot \& Andrews, 1992) and used quarterly 
time series data over the period of 1990Q1-2006Q4 to capture the drastic effects of AFC macroeconomic structural changes, which we also realized the paramount importance of this research because Lao PDR was one of the most affected countries from AFC and previous empirical evidence has not examined in case of Lao PDR.

More significantly, this research will provide new crucial information for the innovative development of research in Lao PDR and would be considerable momentum in the future research. The outcomes could be also one of useful mechanisms and essential directions in formulating and enriching the policy development, and enables to be adopted as the new economic tools for policy makers to cultivate more intimate insights concerning the devastating effect of AFC. This article is structured as following: Section 2 expounds literature reviews. Section 3 demonstrates research methodology and data collection including model specification. Section 4 provides research findings (empirical evidence) and interpretation results, and Section 5 consists of conclusions and policy implications respectively.

\section{Literature Reviews}

\subsection{Empirical Evidences}

Since the AFC commenced in the mid of 1997, numerous countries specifically Southeast Asian nations had abandoned to incredible nightmare from disastrous losses. AFC has been notable phenomenon and paid special interests by economists and various researchers in attempting to estimate the negative effects of AFC on the most affected countries and other nations. Similarly, countless economists and financial economists have been adopting the incident of Asian financial crisis as a crucial dummy variable to analyze various macroeconomic mechanisms as well as the effects of it on economic structural systems. Although, the Asian financial crisis had been traversed for two decades. Nevertheless, it has been becoming an invaluable experience and epitome for a great deal of nations, which numerous scholars have proposed disparate notions on the impacts of AFC on macroeconomic structural changes. Therefore, such the drastic crisis is being considered in empirical researches extensively.

Many seminal studies namely (Harvie \& pahlavani, 2006) examined the Effects of AFC on the Korean Economy. The outcomes indicated that AFC firstly influenced on exchange rate, followed by money supply and gross domestic product before affecting on inflation and interest rate respectively. While (Joh, S.W, 1999) conversely put forward that poor corporate governance caused in occurring Asian financial crisis in 1997 in the shape of companies' inaccurate financial information, financial institutions were insufficiently monitored, few legal rights, protected forms of minority for stakeholders and the repetitive government interference impeded independent decision making for banks and minimized the utility of financial institution monitoring. Some empirical studies also affirmed the absence of evidence that credit flows directed to a relative more profitable sectors for both before and after AFC, and credit flows were not contributed to improve the performance of economy for favorable industries (Borensztein, E. and Lee, J.W, 1999); when the structural break was neglected in time series analysis, the existence of cointegration and bogus rejections will be occurred (Leybourne \& Newbold, 2003).

Some scholars confirmed there was the absence of significant improvement in the integration of intra-regional financial market after the crisis because the measures implemented after the devasting crisis in 1997 was not effectively affected the regional financial integration (Ibrahim, 2009). Other researches also embodied that variables were not stationary or held unit root on the basis of traditional unit root test became stationary property after contemplating the presence of possible structural breaks in time series data. The outcomes were also significantly statistical, the endogeneity of structural break concurred with the spanning of major economic shock to Lebanese economy (Harvie et al., 2006). In connection with this, (Pahlavani et al., 2005) utilized two econometric models notably Innovational Outlier model (IO) and Additive Outlier model (AO) to identify the specific point of structural break and the results demonstrated that the structural breaks found to be simultaneous with significant policy changes in the course of financial deregulation.

Similarly, (Knowles et al., 1999) studied the social effects of Asian financial crisis by selecting from six countries such as: Thailand, Lao PDR, Indonesia, Philippine, Malaysia and Republic of Korea. The outcomes revealed and asserted that it was required to further monitoring and the assessment of social reflects, which the AFC provides a difficult opportunity to learn the function of existing social systems under duress. However, in the event that lessons were adequate to document and effective communication to other aspects (policy makers), the experiences in the course of crisis could provide a useful guidance for policy reform and AFC demonstrated that the pivotal effort will be necessary to direct for the additional development of social safety nets throughout the regions; while (Kochhar et al., 1998) proposed the resolutions of AFC were to ponder the significance of tight monetary policy for the stability of exchange rate, comprehensive structural reforms and flexible fiscal policy, they also recommended that the crisis could be circumvented by implementing the assiduous bank supervision, disclosure of transparent data. robust governance, appropriate macroeconomic policies and accurate forecast policymaking.

By way of contrast, (Chang et al., 1998) conversely took exception that the crisis arose because traditional mechanisms of financial regulations and industrial policy dismantled rather than perpetuation of conventional 
regime, and the pathology of corporate governance system was not a main reason for crisis. Similarly, (Corsetti et al., 1999) strongly affirmed AFC reflected on policy and structural distortions in a great deal of nations and regions. Meanwhile, AFC engendered to the slump of asset prices, exchange rate and economic activities to be more drastic from the initial weak circumstances, the study also recommended an effective way to assist in recovering Asian countries composed of the process of accelerated debt restructure, corporate debt minimization, providing new priority of financing for working capital and trade, and government's active role should be taken into account so as to restructure comprehensive approach of various banks and financial institutions. Nevertheless, (Marie et al., 2006) put forward some arguments that the state minimized to control the development of bureaucracies more than finance and managerial system for direct decision making debilitated the institutional ability of the bureaucrats to hamper the policies accommodation before and after AFC. In addition, a tradition of strategic regulatory instruction was implicated with the favor of economic implementation.

\subsection{Notions of Zivot-Andrews Structural Break}

Over the decades that Zivot-Andrews was published the best-know masterpiece for unit root hypotheses testing based on structural break (Zivot \& Andrews, 1992) that augmented and developed from seminal empirical evidences. For the stationary test of structural break, the basic notion of Zivot-Andrews structural break has been well known as the problem of structural variation and its consequences taken place in a one-time structural break. Therein, the traditional unit root testing still has some shortcomings that could not accurately explain a specific major incident occurring in economic system. Notwithstanding, there may be a number of reasons and various events that conduce/affect to a structural change for macroeconomic mechanisms specifically Asian financial crisis, global financial crisis, economic crisis, policy reform and other major incidents.

On balance, numerous researchers believe that macroeconomic variables entail to be robustly addressed some defects originated from the conventional approach in order to ensure the absence of bogus estimation in unit root testing for time series analysis. To capture a specific major incident, it is enormously pivotal to test the structural stability of initial hypothesis against the trend-stationary alternative hypothesis for a peculiar period of structural break (a one-time structural break). Likewise, the concept of Zivot \& Andrews has fundamentally posited that the possibility of structural variation must be allowed in the specification of an estimated model and then, the outcomes will be unbiased estimation, which the unit root hypotheses of a one-time structural break can be seen from the seminal previous masterpieces (Leybourne \& Newbold, 2003; Pahlavani et al., 2005; Perron, 1989; Perron, 1997).

Some seminal papers put forward the key postulations that break point in the trend function will be considered to be constant and independently selected for time series data (Perron, 1989; Perron, 1990). In the main, a specific trend-stationarity of any structural break is predominantly posited to be known a priori under the condition of asymptotic distribution theory. On the contrary, other scholars demonstrated and argued that taking into account the break period to be an exogenously known incident can nullify the distribution theory of underlying ordinary test (Christiano, 1992; Vogelsang \& Perron, 1998). Similary, in order to disentangle aforesaid defects and some arguments from conventional unit root testing, (Lumsdaine \& Papell, 1997; Perron, 1997; Bai \& Perron, 2003; Zivot \& Andrews, 1992) proposed disparate notions in the estimation of a specific point of break period and averred that the endogenous approach will help to minimize the biased outcomes based on the general unit root testing.

\section{Data and Methodology \\ 3.1 Data}

To investigate the drastic effects of Asian financial crisis on macroeconomic structural changes in Lao PDR, we employ the structural break proposed by (Zivot \& Andrews, 1992) and apply the quarterly time series data during 1990Q1-2006Q4. The key macroeconomic indicators using in this paper are consisted of exchange rate (lnEXC), broad money (lnM2), consumer price index (CPI), total reserve (lnTR), real interest rate (RIR), current GDP (lnGDP) and GNI (lnGNI), gross capital formation (lnGCF), inflation rate based on GDP deflator (IFL), household's expenditure (lnHE) and broad money to GDP (lnBGDP), which those variables are obtained from Word Bank and UN stats. EViews version 10 will be used to capture the drastic effects of Asian financial crisis on macroeconomic structural changes in Lao PDR.

\subsection{Unit Root Testing}

The problems of time series analysis have long been discussed in numerous literature reviews for decades. It is considerable concept for researchers to decide whether the considering techniques (Models) are suitable in practical application in order to circumvent the inefficient estimation and wrongly applied for interpreted results. Similarly, many econometricians affirmed that most of time series data are not stationary characteristics at the order of I (0) and they are predominantly stationary at first difference I (1). Nevertheless, there are still many methods to detect and take care of unit root problem (Non-stationary) proposed by a great deal of economists 
(Dickey \& Fuller, 1979; Dickey \& Fuller, 1981; Dickey, Hasza, \& Fuller, 1984; Phillips \& Perron, 1988; Kwiatkowski, Phillips, Schmidt, \& Shin,1992), which these techniques have extensively been adopted for time series analysis.

\subsection{Model Specification}

To examine the drastic effects of Asian financial crisis on economic structural changes in Lao PDR, we employs the version of structural break for unit root testing followed by the best known technique introduced by (Zivot \& Andrews, 1992), which posited that the time of break point must be estimated rather than postulating as an exogenous phenomenon. Therein, Zivot \& Andrews also contemplated the trend-stationary alternative presume as following equations:

$$
\begin{array}{ll}
\text { Model (A): } & y_{t}=\mu_{1}+\beta t+\left(\mu_{2}-\mu_{1}\right) D U_{t}+e_{t}, \\
\text { Model (B): } & y_{t}=\mu+\beta_{1} t+\left(\beta_{2}-\beta_{1}\right) D T_{t}+e_{t}, \\
\text { Model (C): } & y_{t}=\mu_{1}+\beta_{1} t+\left(\mu_{2}-\mu_{1}\right) D U_{t}+\left(\beta_{2}-\beta_{1}\right) D T_{t}+e_{t},
\end{array}
$$

Where Model (A) allows an exogenous change in the level of time series, Model (B) permits an exogenous change for growth rate and Model (C) determines for both changes (Least restrictive hypothesis) between Model (A) and (B) respectively. Similarly, it is endogenously determined the time of structural breaks, which ZA also took exception that the outcomes of unit root hypotheses proposed by previous tests (traditional methods) as well as the most popular application introduced by (Dickey \& Fuller, 1979; Dickey \& Fuller, 1981; B. Y. P. Perron, 1989) may be inverse and have some shortcomings in term of accurate estimation under considering model. Th form of a one-time structural break under Zivot \& Andrews can be constructed as following equations:

$$
\begin{array}{ll}
\mathrm{H}_{0}: & y_{t}=\mu+y_{t-1}+e_{t} \\
\mathrm{H}_{1}: & y_{t}=\hat{\mu}+\hat{\theta} D U_{t}\left(\widehat{T}_{b}\right)+\hat{\beta} t+\hat{\gamma} D T_{t}\left(\widehat{T}_{b}\right)+\hat{\alpha} y_{t-1}+\sum_{j=1}^{k} \hat{c}_{j} \Delta y_{t-j}+\hat{e}_{t}
\end{array}
$$

Given $y_{t}$ denotes a one structural break of each time series (variables), $T_{b}$ (A specific time of break) is determined to lessen a one-side of T-statistics test of $\alpha=1$ for equation (1) and (2) successively. That is, a break point will be selected as the least favorable benchmark to the initial postulation. The second model (equation 2) is constructed based on Model (C) of Zivot and Andrews (Zivot \& Andrews, 1992), which can be adjusted the possibility of a shift in the intercept and the trend of break. Likewise, ZA ponders two alternatives where a structural break merely influences on the intercept (model A) and the trend (model B), the model C considers as the least restrictive assumption likened to the previous two models (model A and B).

This empirical evidence examines the drastic effect of Asian financial crisis on economic structure changes in Lao PDR will be based on the Model C. Therein, $D T_{t}$ is dummy variables which represents a break trend arising at a time period $T_{b}$, where $D U_{t}=1$ if $t>T_{b}$ and $0=$ otherwise, $D T_{t}$ equals to $\left(t-T_{b}\right)$ if $\left(t>T_{b}\right)$ and equals to 0 for otherwise, $D U_{t}$ is another dummy variable that demonstrates a variation of the intercept and the null hypothesis will be rejected if coefficient $(\alpha)$ is statistical significance. More importantly, the structural break test of ZA avers that $T_{b}$ can be endogenously estimated by running equation (2) depicted above so as to be determined $T_{b}$ lies on any particular quarterly other than the first and last quarter while the appropriate leg length will be stipulated on the basis of Akaike information criterion (AIC) or T-statistics, the application of ZA technique for the structural changes can be determined by considering the most significant T-statistics which is rejected the initial hypothesis and accepted alternative hypothesis under consideration in the estimated model and so on.

\section{Empirical Outcomes}

\subsection{Overview of the Effects of Asian Financial Crisis in Lao PDR}

As well-known that the inception of Asian financial crisis was derived and transmitted from Thailand to various countries in term of pertinent economic mechanisms and other articulations. The cause of this drastic crisis was because of the application of new policy in Thailand. That is, government of Thailand was forced to float domestic currency due to lacking of foreign currency (US dollar) in economic system. Meanwhile, numerous banks, real estate business and various financial institutions were bankrupted. Likewise, Thailand is one of Laos' neighboring countries and most of economic activities (markedly export, import and so on) have been depending on such this major trading partner. Indeed, it was enormously suffered from the crisis unavoidably since many transactions of economy were conditional on Thailand. Years ago, consumer price index in Laos was gradually increased at stable level. Up to 1996, the consumer price index stood at 7.02, with a negative effect of crisis was intensely rose to 8.95 in the year of crisis. However, owing to AFC took place in the mid of 1997 and its effect transmitted to next period (next few years) which led to accrue at 17.09 and continued to be doubled increase by 17.09 and 38.49 in 1998 and 1999 respectively. As a result, the indicator of consumer price index has been increasing rapidly after hurting from Asian financial crisis.

Obviously, the AFC was impacted on the level of domestic goods prices and even foreign products from Thailand by virtue of being Laos' major trading partner. During AFC, Lao PDR had suffered and hurting by the rapid increase of domestic inflation rate as well as a dramatic rise of goods price and regarded to be the highest 
level in the history of Laos particularly in 1996, inflation rate stood at $13.73 \%$ and continued to climb at $84.50 \%$ in 1998. In turn, it dramatically rose to $127.97 \%$ in 1999 and was implicit that the inflation rate in Laos during AFC had drastically transmitted its negative effect to later on year, and it also continued to reflect on the gross domestic product as well. To put it another way, the economic growth slightly fell down from $6.93 \%$ in 1996 changed over $6.87 \%$ in 1997 owing to the late seed of Asian financial crisis which engendered to a slight decline of economic growth (1997) likened to the previous year. From this point, GDP growth was enormously dropped and approximately represented 3.97\% in 1998 (after a year of AFC).

Table 1. Depicts Macroeconomic Variables during AFC in Lao PDR

\begin{tabular}{|c|c|c|c|c|c|c|c|c|c|c|}
\hline Year & CPI & TR & RIR & IFL & GDPG & EXC & GNIG & M2 & M2/TR & M2G \\
\hline 1989 & 2.71 & 0.56 & - & 55.27 & 14.19 & 551.33 & 19.21 & 9.88 & 8.5 & - \\
\hline 1990 & 3.67 & 0.47 & - & 37.91 & 6.7 & 707.75 & 21.22 & 7.24 & 7.48 & 7.84 \\
\hline 1991 & 4.16 & 1.85 & 11.53 & 12.97 & 4.3 & 702.08 & 18.78 & 7.11 & 2.11 & 15.73 \\
\hline 1992 & 4.57 & 2.4 & 18.87 & 5.99 & 5.56 & 716.08 & 9.7 & 9.47 & 2.32 & 49.01 \\
\hline 1993 & 4.86 & 3.51 & 12.72 & 11.18 & 5.91 & 716.25 & 17.73 & 13.23 & 2.52 & 64.59 \\
\hline 1994 & 5.19 & 3.26 & 15.13 & 7.7 & 8.16 & 717.67 & 16.12 & 14.99 & 3.43 & 31.93 \\
\hline 1995 & 6.21 & 4.58 & 5 & 19.69 & 7.03 & 804.69 & 13.99 & 13.62 & 2.43 & 16.4 \\
\hline 1996 & 7.02 & 7.79 & 11.67 & 13.73 & 6.93 & 921.02 & 6.21 & 14.19 & 1.51 & 26.73 \\
\hline 1997 & 8.95 & 5.04 & - & 19.35 & 6.87 & 1259.98 & -8.68 & 18.44 & 2.75 & 65.76 \\
\hline 1998 & 17.09 & 4.76 & -29.93 & 84.5 & 3.97 & 3298.33 & -27.07 & 20.51 & 2.24 & 113.28 \\
\hline 1999 & 38.49 & 5.28 & -42.1 & 127.97 & 7.31 & 7102.03 & 15.16 & 14.95 & 1.61 & 78.36 \\
\hline 2000 & 48.14 & 5.67 & 5.77 & 24.8 & 5.8 & 7887.64 & 15.98 & 16.54 & 1.99 & 46.04 \\
\hline 2001 & 51.91 & 5.84 & 15.89 & 8.87 & 5.75 & 8954.58 & 2.36 & 16.34 & 1.91 & 13.72 \\
\hline 2002 & 57.42 & 6.83 & 21.65 & 6.32 & 5.92 & 10056.33 & -0.34 & 19.96 & 1.62 & 37.6 \\
\hline 2003 & 66.32 & 10.27 & 15.03 & 13.45 & 6.07 & 10569.04 & 12.76 & 19.92 & 1.57 & 20.07 \\
\hline 2004 & 73.26 & 9.31 & 16.77 & 10.69 & 6.36 & 10585.38 & 18.82 & 20.58 & 1.77 & 21.64 \\
\hline 2005 & 78.51 & 9.43 & 16.75 & 8.64 & 7.11 & 10655.17 & 17.64 & 19.08 & 1.69 & 7.87 \\
\hline 2006 & 83.64 & 12.14 & 17.32 & 10.81 & 8.62 & 10159.94 & 22.19 & 20.09 & 1.5 & 26.72 \\
\hline 2007 & 87.54 & 14.19 & 19.6 & 7.44 & 7.6 & 9603.16 & 24.92 & 24.1 & 1.44 & 38.72 \\
\hline 2008 & 94.22 & 15.51 & 13.9 & 8.86 & 7.82 & 8744.22 & 27.31 & 24.29 & 1.51 & 18.31 \\
\hline 2009 & 94.36 & 14.4 & 28.54 & -2.93 & 7.5 & 8516.05 & 9.24 & 30.82 & 1.96 & 32.41 \\
\hline 2010 & 100 & 16.85 & 12.29 & 9.2 & 8.53 & 8258.77 & 17.78 & 36.19 & 2.34 & 39.13
\end{tabular}

Note: (CPI refers to "consumer price index", TR denotes "total reserves as \% of total external debt", RIR means "real interest rate", IFL represents "inflation rate based on GDP deflator", GDPG stands for "gross domestic product growth or annual growth", EXC is "exchange rate \$ 1 US/domestic currency (Kip)", GNIG signifies as "gross national income growth", M2 refers to "broad money as \% of GDP", M2/TR means "broad money to total reserve ratio" and $\mathrm{M} 2 \mathrm{G}$ determines as "broad money growth in each year" respectively.

Similarly, AFC was also affected on total reserves (\% of total external debt) in term of a decline from $7.79 \%$ in 1996 to $5.04 \%$ in 1997 and slightly decreased to be $4.76 \%$ in 1998 thanks to the subsequent negative impacts continued to next year. Also, international reserves (foreign reserves) in Lao PDR has been controlling by central banks (bank of Lao PDR: BOL). To recover from such the disastrous crisis, BOL may have to obtain special assistance from international organization such as International Monetary Fund (IMF) to address and revive economic system as well as accommodating of new appropriate economic structures, and solving various macroeconomic shocks. The negative influence of ACF also resulted to a change in real interest rate in term of deterioration specifically it dropped down to negative rate $(-29.93 \%)$ in 1998 . From this point, it also fell to be $42.10 \%$ in 1999 due to the bankruptcy of banks, financial institutions, numerous firms were predominantly out of business and had no confidence of additional investments due to stagnant economy and was seemingly under the economic meltdown circumstance. Therefore, the existing banks and pertinent financial institutions had not provided loans and were still kept balance of their funds in order to retain in some emergencies in term of financial statement, whilst currency in circulation in economic system was still in the period of fierce fluctuation.

Furthermore, Lao PDR intensely ached by the depreciation of exchange to US dollars. The devaluation of domestic currency (LAK: Lao kip) compared to foreign currency (US dollar) was enormously depreciated from \$ 1 dollar/921.02 KIP (LAK) in 1996, changed over to be \$ 1 dollar/1259.98 KIP (LAK) in 1997, and roughly represented $36.80 \%$ of additional ratio. Likewise, Lao KIP continued to dramatically depreciate in the next year (1998), approximately $\$ 1$ dollar/3298.33 KIP and increased $161.77 \%$ compared to last year due to lacking of US dollar currency together with the high demands of foreign currency (US dollar) in the economic system. Also, the Lao KIP (LAK) continually remained depreciation and exchange rate between US dollar and Lao KIP (LAK) was $\$ 1$ dollar/7102.03 KIP in 1999, which an increase rate approximately rose at $115.32 \%$. As a result, Lao PDR had immensely hurting from AFC in term of domestic currency depreciation, high demand for foreign currency (i.e. 
US dollar) and this incident led to be an incredible seed for depreciation of Lao KIP over the decades. This phenomenon treated as the huge losses of currency devaluation in the Laos' history and it has been transmitting to be a chronic puzzle in economic mechanism system to date.

More fascinatingly, it was seen that the gross national product growth (GNPG) had become negative effect. That is, the GNP growth of Lao PDR drastically declined from positive growth at $6.21 \%$ in 1996 turned into the negative direction around $-8.68 \%$ in 1997 and still continued to drop down $-27.07 \%$ compared to the previous year. On the contrary, the amount of broad money (M2: money supply) to gross domestic product (GDP) also rose from $14.19 \%$ in 1996 to 18.44 in 1997 and continually accrued $20.51 \%$ of total GDP proportion. Obviously, the lacking of foreign currency caused to depreciate of exchange rate and there was a large quantity of money in economic system due to Lao government may have to implement monetary policy by supplying money as well as injection of myriad money in economic system in order to recover the crisis and this engendered to aggrandize broad money. Therefore, the ratio of broad money to GDP went up to $20.51 \%$ in 1998 , whereas it conduced to affect the broad money to total reserve ratio in term of decrease or negative reflect. Say, it dropped from $2.75 \%$ to $2.24 \%$ in 1997 and 1998 respectively. Meanwhile, the broad money to total reserve proceeded to fall by $1.61 \%$ and its growth (Broad money growth) also aggrandized from 26.73\% in 1996, changed over 65.76\% in 1997 and increasingly remain to be at $113.28 \%$ after the year of crisis (1998). All in all, the drastic effect of Asian financial crisis is mostly affected to macroeconomic structure changes next one, two and three years. That is, most of macroeconomic indicators suffered with the minimal shocks in the short term and obtained the drastic shocks in the long run economic mechanism system and so forth.

\subsection{Empirical Evidence}

By deriving the aforesaid incident analysis, this paper uses 11 key macroeconomic indicators to capture the drastic effect of Asian financial crisis (AFC) on macroeconomic structural changes in Lao PDR by using the best-known technique of structural break unit root testing proposed by (Zivot \& Andrews, 1992). As presented in table 2, the findings of empirical results aver that real exchange rate (lnEXC), consumer price index (CPI), broad money (lnM2) and total reserve (lnTR) are stationary, whilst the remaining seven variables have become non-stationary, which indicates that the most significant indicators for the estimation of structural breaks are statistically significant and corresponding with the Asian financial crisis and economic meltdown (see table 2). That is, real exchange rate, consumer price index, broad money and are endogenously determined a specific point of structural break corresponded and closed to Asian financial crisis (AFC) as well as economic turbulence, where those variables had been broken in the second quarter of AFC year. More fascinatingly, the structural break of total reserves (lnTR) commenced after the Asian financial crisis and was at the first quarter of 1998 (1998Q1), which affirmed that the AFC transmitted its negative impact to total reserve in the long run impact.

Table 2. The Result of Zivot \& Andrews' Structural Break

\begin{tabular}{|l|c|c|c|c|c|}
\hline \multirow{2}{*}{ Variables } & \multicolumn{4}{|c|}{ Zivot \& Andrews Structural Break Unit Root Testing } \\
\cline { 2 - 6 } & $\begin{array}{c}\text { Time of } \\
\text { Break }\end{array}$ & Lag & $\begin{array}{c}\text { T- } \\
\text { stats }\end{array}$ & Conclusion & $\begin{array}{c}\text { Break Time } \\
\text { Incidents }\end{array}$ \\
\hline Consumer Price Index (CPI) & $1997: \mathrm{Q} 2$ & 2 & $5.52^{* *}$ & Stationary & $\begin{array}{c}\text { AFC and economic } \\
\text { downturn }\end{array}$ \\
\hline Real Exchange Rate (lnEXC) & $1997: \mathrm{Q} 2$ & 2 & $\begin{array}{c}6.87^{* *} \\
{ }^{*}\end{array}$ & Stationary & $\begin{array}{c}\text { AFC and economic } \\
\text { downturn }\end{array}$ \\
\hline Broad Money (lnM2) & $1997: \mathrm{Q} 2$ & 2 & $5.5^{* *}$ & Stationary & $\begin{array}{c}\text { AFC and economic } \\
\text { downturn }\end{array}$ \\
\hline Total Reserve (lnTR) & $1998: \mathrm{Q} 1$ & 4 & $5.24^{* *}$ & Stationary & Recover from AFC \\
\hline Real Interest Rate (RIR) & $2000: \mathrm{Q} 1$ & 4 & 4.05 & Non-Stationary & Recover from AFC \\
\hline Current GDP (lnGDP) & $1997: \mathrm{Q} 2$ & 2 & 3.5 & Non-Stationary & $\begin{array}{c}\text { AFC and economic } \\
\text { downturn }\end{array}$ \\
\hline Current GNI (lnGNP) & $1999: \mathrm{Q} 2$ & 2 & 3.79 & Non-Stationary & Recover from AFC \\
\hline $\begin{array}{l}\text { Gross Capital Formation (ln } \\
\text { GCF) }\end{array}$ & $1998: \mathrm{Q} 1$ & 4 & 3.48 & Non-Stationary & Recover from AFC \\
\hline Inflation Rate (INL) & $2001: \mathrm{Q} 1$ & 4 & 3.77 & Non-Stationary & Recover from AFC \\
\hline Household Expenditure (lnHE) & $2002: \mathrm{Q} 1$ & 4 & 2.11 & Non-Stationary & Recover from AFC \\
\hline $\begin{array}{l}\text { Broad Money to GDP } \\
\text { (lnBGDP) }\end{array}$ & $1998: \mathrm{Q} 4$ & 4 & 3.48 & Non-Stationary & Recover from AFC
\end{tabular}

Note: we considered the year of Asian financial crisis as economic recession/economic meltdown/economic turbulence and pondered as the period of economic recovery after $1997, * * *, * *, *$ denotes the significance level $1 \%, 5 \%$ and $10 \%$ of null hypothesis rejection by critical values $-5.57,5.08,4.82$ respectively (Zivot \& Andrews, 1992). 

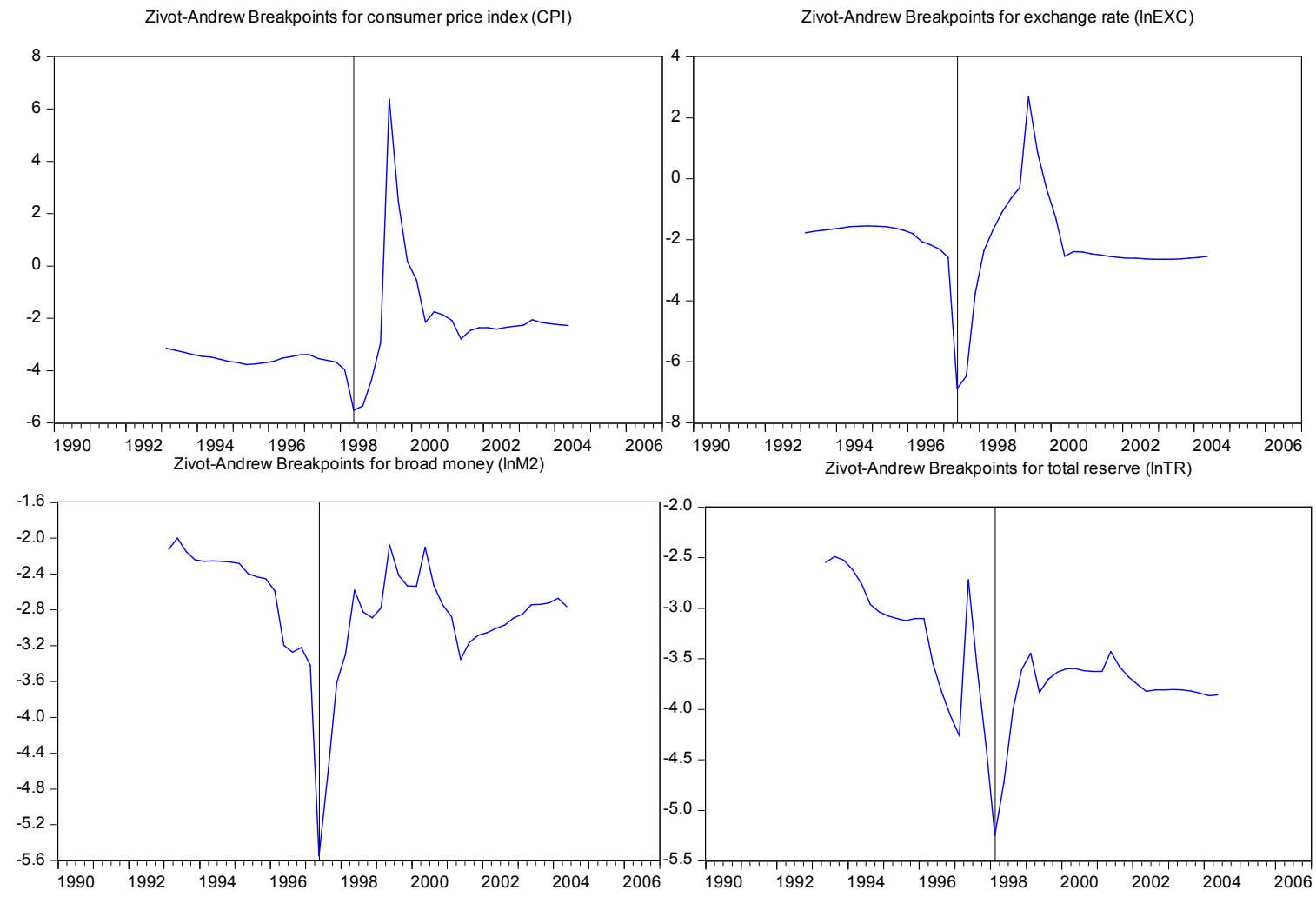

Figure 1. Shows the result of Zivot-Andrews Breakpoints for each variable

Similarly, the empirical evidences also confirmed that the most significant period of structural break for real exchange rate, consumer price index and broad money took place in the second quarter (1998Q2), which were in the spanning of extreme financial crisis and economic meltdown. In other words, the drastic effect of AFC initially impacted on real exchange rate, followed by consumer price index and broad money, whereby we can epitomize that the results are consistent with the previous empirical evidence (Harvie \& pahlavani, 2006). Those shocks intensely transmitted to other variables as well as macroeconomic structures, while the structural break of total reserve (lnTR) occurred in the first quarter of 1998 (1998Q1) and that was in the period of economic recovery. At the same time, the impact of AFC still remained as the severe circumstance. Therefore, Lao government (Central bank) had initiated and implemented circumspect policy to revive economic mechanism system, which led to a decline of total reserves and its structural break had found at the first quarter of 1998 (1998Q1). Although, the null assumption of remaining seven macroeconomic variables namely real interest rate, current gross domestic product, current gross national product, gross capital formation, Inflation Rate based on GDP deflator, household expenditure and broad money to GDP cannot be rejected. In other words, the rest of variables are not stationary (unit root exists). Nevertheless, macroeconomic variables were predominantly affected by AFC in the long run shock rather than short run impulse. These macroeconomic variables also have negative impacts but not statistically significant after the Asian financial crisis and treated as the time period of new economic recovery/economic structural re-adjustment.

All things considered, the empirical outcome strongly aver that the AFC as well as economic meltdown in 1997, which derived from Thailand rapidly had extreme impacts on direct financial indicators and other macroeconomic variables notably real exchange rate $(\operatorname{lnEXC})$, consumer price index, broad money and total reserve, while real interest rate had not been affected in this period, this may be because central bank took careful measures to control an increase in real interest rate that may drastically hurt the economic meltdown and the rapid implementation of agreement with the IMF for a financial rescue package as well as rapid agreement with international banks will assist to strengthen and recover macroeconomic structural mechanism and so on.

\section{Conclusions and Remarks}

Lao PDR has enormously hurting from the drastic effects of Asian financial crisis since many economic transactions are conditional on her major trading partner namely Thailand. The seed of Asian financial crisis from Thailand was inevitably affected on Lao economic structural changes as well as macroeconomic mechanism systems. Therefore, this paper aims to capture the drastic effects of Asian financial crisis on macroeconomic structural changes in Lao PDR by employing a special technique and advanced econometric method. Say the 
structural breaks of unit root testing introduced by (Zivot \& Andrews, 1992). The quarterly time series data was also adopted during the period of 1990Q1-2006Q4 and estimated by EViews version 10.

The empirical evidence strongly corroborated that Asian financial crisis has rapidly extreme impacts directly on macroeconomic structural changes and other mechanism systems particularly real exchange rate, consumer price index, broad money and total reserve, while real interest rate has not been adverse influence in this period, which our empirical evidence have been consistent with the previous empirical study (Harvie \& pahlavani, 2006). More considerably, the results also asserted that the disastrous events of Asian financial crisis had initially affected on exchange rate (lnEXC: 1997Q2), followed by consumer price index (CPI:1997Q2), broad money (lnM2: 1997Q2) with a $1 \%, 10 \%$ and $10 \%$ significance level. In addition, we surprisingly found that total reserve was affected by Asian financial crisis in the first quarter of 1998 (lnTR: 1998Q1) that was a recovering period from $\mathrm{AFC}$ and transmitted its shock to other macroeconomic variables in long run.

As the drastic effects of Asian financial crisis occurred in 1997, Lao PDR had been suffered with major obstacles and arduous puzzles resulting to the economic structural changes. Likewise, together with the devastating experience from Asian financial crisis, our empirical evidence has markedly uncovered and would suggest that Lao government should pay special attention and take circumspect steps to strictly control the fluctuation of exchange rate between domestic and foreign currency, to retain the stability of macroeconomics mechanism systems in order to establish the appropriate policy towards the balance of trade, current account, balance of payments. It is crucial for policy makers to control the amount of money supply (broad money) by implementation of monetary policy for both the short run and long run implementation. More importantly, pertinent aspects should take stringent controls on the level of price and real interest rate in the marketplace so as to prevent the contingent and potential crisis in the future. The last but not least, our result is seemingly in line with previous literature review (Harvie \& pahlavani, 2006). From this point, it is important for Lao PDR to accommodate and exchange the practical application of monetary and fiscal policies with other countries in order to accommodate appropriate macroeconomic policy consistent with the status quo circumstance and future direction.

\section{References}

Bai, J., \& Perron, P. (2003). Critical values for multiple structural change tests. The Econometrics Journal, 6(1), 72-78.

Borensztein, \& Lee. (1999). Credit Allocation and Financial Crisis in Korea. IMF Working Papers, 99(20), 1. https://doi.org/10.5089/9781451843828.001.

Chang, H.-J., Park, H.-J., \& Yoo, C. G. (1998). Interpreting the Korean crisis: financial liberalisation, industrial policy and corporate governance. Cambridge Journal of Economics, 22(6), 735-746.

Corsetti, G., Pesenti, P., \& Roubini, N. (1999). What caused the Asian currency and financial crisis? Japan and the World Economy, 11(3), 305-373.

Dickey, D. A., \& Fuller, W. A. (1979). Distribution of the Estimators for Autoregressive Time Series With a Unit Root. Journal of the American Statistical Association, 74(366), 427. https://doi.org/10.2307/2286348.

Dickey, D. A., \& Fuller, W. A. (1981). Likelihood Ratio Statistics for Autoregressive Time Series with a Unit Root. Econometrica, 49(4), 1057. https://doi.org/10.2307/1912517.

Dickey, D. A., Hasza, D. P., \& Fuller, W. A. (1984). Testing for Unit Roots in Seasonal Time Series. Journal of the American Statistical Association, 79(386), 355-367.

Harvie, C., and M. Pahlavani. (2006). Testing for Structural Breaks in the Korean Economy 1980-2005: An Application of the Innovational Outlier and Additive Outlier Models. Journal of the Korean Economy, Vol 7, No 2, pp.1-29.

Harvie, C., and M. Pahlavani. (2006). Effects of the Asian Financial Crisis on the Korean Economy: Some Further Empirical Evidence. Retrieved from. http://citeseerx.ist.psu.edu/viewdoc/download?doi=10.1.1.360.9379\&rep=rep1\&type=pd.

Ibrahim, S. (2009). East Asian financial integration: A cointegration test allowing for structural break and the role of regional institutions. International Journal of Economics and Management, 3(1), 184-203.

Joh, S.W. (1999), “The Korean Corporate Sector: Crisis and Reform,” KDI Working Paper No.9912.

Knowles, J., Pernia, E., \& Pernia, E. (1999). Social Consequences of the Financial Crisis in Asia. Papers, 16(60).

Kochhar, K., Loungani, P., \& Stone, M. R. (1998). The East Asian Crisis: Macroeconomic Developments and Policy Lessons. In IMF Working Papers (Vol. 98, Issue 128, p. 1). https://doi.org/10.5089/9781451935547.001.

Kwiatkowski, D., Phillips, P. C., Schmidt, P., \& Shin, Y. (1992). Testing the null hypothesis of stationarity against the alternative of a unit root. Journal of Econometrics, 54(1), 159-178.

Leybourne, S. J., \& Newbold, P. (2003). Spurious rejections by cointegration tests induced by structural breaks. Applied Economics, 35(9), 1117-1121.

Lumsdaine, R. L., \& Papell, D. H. (1997). Multiple Trend Breaks and the Unit-Root Hypothesis. Review of Economics and Statistics, 79(2), 212-218. https://doi.org/10.1162/003465397556791. 
Marie, J. J. S., Hansen, K. N., \& Tuman, J. P. (2006). The Asian economic crisis and bureaucratic development: a veto player analysis. International Relations of the Asia-Pacific, 7(1), 1-22. https://doi.org/10.1093/irap/lci147.

Pahlavani, M., Valadkhani *, A., \& Worthington, A. C. (2005). The impact of financial deregulation on monetary aggregates and interest rates in Australia. Applied Financial Economics Letters, 1(3), 157-163.

Perron, P. (1989). The Great Crash, the Oil Price Shock, and the Unit Root Hypothesis. Econometrica, 57(6), 1361. https://doi.org/10.2307/1913712.

Perron, P. (1990). Testing for a Unit Root in a Time Series With a Changing Mean. Journal of Business \& Economic Statistics, 8(2), 153-162.

PHILLIPS, P. C. B., \& PERRON, P. (1988). Testing for a unit root in time series regression. Biometrika, 75(2), 335-346.

Vogelsang, T. J., \& Perron, P. (1998). Additional Tests for a Unit Root Allowing for a Break in the Trend Function at an Unknown Time. International Economic Review, 39(4), 1073. https://doi.org/10.2307/2527353.

YAMAZAWA, I. (1998). THE ASIAN ECONOMIC CRISIS AND JAPAN. The Developing Economies, 36(3), 332-351.

Zivot, E., \& Andrews, D. W. K. (1992). Further Evidence on the Great Crash, the Oil-Price Shock, and the UnitRoot Hypothesis. Journal of Business \& Economic Statistics, 10(3), 251. 